\title{
Recurrent Hepatitis C Virus (Genotype 4) Infection after Living Donor Liver Transplantation: Risk Factors and Outcome
}

Emad Hamdy Salem ${ }^{1 *}$, Mohammed Taha' ${ }^{1}$, Amr Aziz' ${ }^{1}$, Ayman Alsebaey², Khaled Abou El-Ella1 and Tarek Ibrahim ${ }^{1}$

${ }^{1}$ Hepatobiliary Surgery Department, National Liver Institute, Menoufiya University, Shibin El-Kom, Menoufiya, Egypt

${ }^{2}$ Hepatology Department, National Liver Institute, Menoufiya University, Shibin El-Kom, Menoufiya, Egypt

\begin{abstract}
Objectives: The recurrence of HCV post liver transplantation endangers patient and graft survival. The aim of this study is to analyze the risk factors for HCV recurrence, the effect of the recurrence and its management on the outcome of liver transplantation.

Materials and methods: After exclusion of the 6 months mortality, dual HCV and HCC patients, about fifty five HCV related LDLT patients were enrolled in the study and were followed up from 6 to 60 months. Demographic, preoperative, intraoperative and postoperative data were studies. HCV recurrence was defined by elevated transaminases, positive serum HCV RNA and liver biopsy findings. Univariate and multivariate analysis were done on all data to detect the favoring factors of HCV recurrence.

Results: HCV recurrence occurred in 21/55 of the patients and one of them developed cirrhosis on follow up. By univariate analysis; CMV infection, mean operative time $(12.490 \pm 1.8952)$, acute cellular rejection and pulse steroids treatment were predictors of HCV recurrence $(P<0.05)$. Multivariate analysis revealed only acute cellular rejection to be a predictor. The overall 1,3 and 5 years' survival of all patients was $94.5 \%, 90.9 \%$ and $90.9 \%$ respectively, while the overall 1,3 and 5 years' survival of patients with and without recurrence was $95.2 \%, 90.5 \%$ and $90.5 \%$ and $94.1 \%, 91.2 \%$ and $91.2 \%$ respectively.

Conclusion: The occurrence of acute rejection was independent predictor of HCV recurrence post LDLT, so its prevention is required to decrease this recurrence. Similarly, prevention of CMV infection and decreasing operative time is important to decrease post-transplant HCV recurrence.
\end{abstract}

Keywords: Living donor liver transplantation; Hepatitis C recurrence; Outcome post LDLT

Abbreviations: ALT: Alanine Transaminase; AST: Aspartate Transaminase; BMI: Body Mass Index; CMV: Cytomegalovirus; Cnis: Calcineurin Inhibitors; Csa: Cyclosporine; FK Or FK-506: Tacrolimus; GRWR: Graft Recipient Weight Ratio; HAI: Histological Activity Index; HCC: Hepatocellular Carcinoma; HCV: Hepatitis C Virus; HCV RNA: Hepatitis C Virus Ribonuclic Acid; HPB: Hepatopancreatobiliary;LDLT: Living Donor Liver Transplantation; LT: Liver Transplantation; MELD: Model for End Stage Liver Disease; MMF: Mycophenolate Mofetil; NLI: National Liver Institute; PCR: Polymerase Chain Reaction; RBV: Ribavirin; RT-PCR: Reverse-Transcription Polymerase Chain Reaction; SRL: Sirolomus; SVR: Sustained Virological Response; ULN: Upper Limit Normal

\section{Introduction}

Living related liver transplantation is a well-accepted therapeutic option for patients with end-stage liver disease caused by variable diseases like, chronic viral hepatitis (in particular hepatitis C, B virus infection), early-stage hepatocellular carcinoma, hepatoblastoma, Budd-Chiari syndrome and primary sclerosing cholangitis [1]. In Egyptian patients who undergo living-donor liver transplantation, hepatitis $C$ virus related end-stage liver disease is the main indication for transplantation. Unfortunately, the recurrence of that infection after transplant is almost universal. It causes graft damage in most cases and is the leading cause of graft loss and the need for retransplant [2]. Recent reports show that $99 \%$ recurrent viremia and $46 \%$ clinical HCV recurrence occur after transplantation for $\mathrm{HCV}[3,4]$.

The risk factors responsible for disease recurrence are not well studied but many reports applied show that: Several factors (donor age, living-donor and donor-recipient matching, virologic features, acute rejection episodes, immunesuppression) have been shown to influence the progression of post-transplant liver disease [2]. Similarly, Cytomegalovirus (CMV) infection has been strongly associated with increased severity of HCV recurrence [5].

Furthermore, antiviral treatment in transplant patients is feasible and does not induce severe immunological effects, so, it is recommended in recurrent $\mathrm{HCV}$ to use antiviral in the form of PEGIFN plus Ribavirin, with good SVR and survival [6].

The study aimed at analysis of the different factors responsible for $\mathrm{HCV}$ recurrence, the effect of the recurrence and its management on the outcome of liver transplantation.

\section{Materials and Methods}

After approval of Institutional Review Board (IRB), and obtaining written informed consents from both donors and recepients, we retrospectively and prospectively analyzed liver transplanted patients in the department of HPB surgery, NLI, university of Menoufiya, Menoufiya, Egypt, in the period from April 2003 to April 2013. During

*Corresponding author: Emad Hamdy Salem, Hepatobiliary Surgery Department National Liver Institute, Menoufiya University, Shibin El-Kom, Menoufiya, Egypt, Tel: 020100 3031128; Fax: 02048 2234685; E-mail: Emadgadsalemaa@yahoo.com

Received December 04, 2013; Accepted January 06, 2014; Published January 14,2014

Citation: Salem EH, Taha M, Aziz A, Alsebaey A, El-Ella KA, et al. (2014) Recurrent Hepatitis C Virus (Genotype 4) Infection after Living Donor Liver Transplantation: Risk Factors and Outcome. J Liver 3: 148. doi:10.4172/2167-0889.1000148

Copyright: () 2014 Salem EH. This is an open-access article distributed unde the terms of the Creative Commons Attribution License, which permits unrestricted use, distribution, and reproduction in any medium, provided the original author and source are credited. 
the period, about 141 out of 200 patient underwent LDLT due HCV related cirrhosis. After exclusion of the 6 months mortality 53 patients, dual HCV and HCC patients 33 patients, about $55 \mathrm{HCV}$ related LDLT patients were enrolled in the study and were followed up from 6 to 60 months. The following data were further analyzed:

\section{Preoperative variables}

Donor's age, gender, blood group, Body Mass Index (BMI) and donor to recipient relation. Recipients' age, gender, blood group, BMI, Child Pugh score, MELD score, antiviral treatment (PegINF/ RBV), endoscopic intervention for esophageal varices (band ligation, sclerotherapy), comorbidity (DM, HTN) and finally CMV infection (CMV IgG, IgM for both donors and recepients ), when CMVIgG was positive, prophylaxis was done using acyclovir $300 \mathrm{mg}$ tid. Really the best drugs are ganciclovir $\left(\right.$ Cymevene $\left.{ }^{\circledR}\right)$, and valaganciclovir $\left(\right.$ Valcite $\left.^{\circledR}\right)$ but they are highly expensive besides their known nephrotoxicity and lethal bone marrow suppression. So acyclovir $900 \mathrm{mg} /$ day for 6 months was given. All donors and recepients were CMVIgM negative before LT.

\section{Intraoperative variables}

Duration of the operation per hours, graft weight (calculated and actual intraoperative weight), calculated and actual graft recipient weight ratio (GRWR), cold ischemia time per minute, warm ischemia time per minute, blood transfusion per unit and finally plasma transfusion per unit.

\section{Postoperative variables}

Immunosuppression protocol: The standard is combined 3 drugs: Calcineurin Inhibitors (CNIs), steroids and Mycophenolate Mofetil (MMF). Tacrolimus (FK506) was prescribed at an initial dose of 0.05$0.1 \mathrm{mg} / \mathrm{kg} /$ day divided every 12 hours ( 9 a.m. and 9 p.m.) and adjusted over time to maintain levels of $10-15 \mathrm{ng} / \mathrm{mL}$ at $0-14$ days, $6-10 \mathrm{ng} / \mathrm{mL}$ at 14-28 days, and 5-8 ng/mL thereafter. MMF was given at an oral dosage of $250-500 \mathrm{mg}$ twice a day to be stopped 6 months later. The initial methylprednisolone dose is $500 \mathrm{mg}$ intraoperatively with a brief taper of prednisone from 240 to $40 \mathrm{mg} / \mathrm{d}$ over 6 days followed by 5-20 $\mathrm{mg} / \mathrm{d}$ maintenance treatment, with complete withdrawal at the end of $3^{\text {rd }}$ month post LDLT. Cyclosporine (CsA) was used when neurotoxicty or nephrotoxicity developed with Tacrolimus. It was given at an oral dosage of $8-10 \mathrm{mg} / \mathrm{kg} / \mathrm{day}$, where blood trough levels were maintained between 150 and $250 \mathrm{ng} / \mathrm{ml}$ in the 1 st 6 months and between 100 and $150 \mathrm{ng} / \mathrm{ml}$ thereafter. When CNIs are contraindicated or their side effects halt their use, Sirolimus (SRL) was given at an initial dose of $3 \mathrm{mg} / \mathrm{m} 2$ and adjusted over time to achieve blood trough levels of approximately $5-8 \mathrm{ng} / \mathrm{mL}$. Biopsy-proven acute rejection episodes were treated with steroid pulses (IV methylprednisolone 200 to $500 \mathrm{mg} / \mathrm{d}$ for 3 days), which were tapered over several days to the baseline dose.

\section{Postoperative follow up protocol to detect HCV recurrence:}

Follow up period from 6 months to 60 months: The follow up was done monthly during the 1 st 6 months, then every 3 months till the 1st year, then every 6 months till the end of follow up ( 60 months).

Diagnosis of HCV recurrence by all of the following: 1- Laboratory results (elevated ALT, AST) $\geq 2$-fold over the normal upper limit. 2Positivity of serum HCV RNA by reverse-transcription polymerase chain reaction (RT-PCR) 3- Routine Core liver biopsies (The biopsy was performed with ultrasonographic guidance and a conventional automatic 16-gauge Tru-cut needle) to assess: a- Fibrosis: evaluated according to The METAVIR (7) and/or Ishak (8) scores. The fibrosis score was measured from 1 to 6 (Trichrome stain was used). b- The inflammatory grading (18 points) (infiltration of the portal tract with mononuclear inflammatory cells, interface hepatitis, spotty necrosis, confluent necrosis). c- The Histological Activity Index (HAI): The sum of spotty necrosis score (from 1 to 4 ), a confluent necrosis score (from 0 to 6), interface hepatitis score (from 0 to 4 ), and a portal inflammation score (from 0 to 4 ) N.B. Other possible diagnoses (particularly cellular rejection) were excluded by the followings: a- Absence of endothelialitis and centrilobular tissue damage. b- Biopsies from patients with HCV infection contain macro or microvesicular steatosis, irregular limiting plates, lobular inflammations, hepatocyte necrosis and reactive changes of hepatocytes. c- Analysis of the liver biopsy by two expert pathologists to avoid inter-observer variation $[7,8]$.

Treatment: Criteria for treatment of recurrent HCV were: staging $>1$ and grading $>4$. All treated patients received PEG-IFN- $\alpha$ 2b (PEG-Intron, Schering Plough, and Kenilworth, NJ, USA) which was administered subcutaneously at a weekly dose of $1 \mu \mathrm{g} / \mathrm{kg}$ of body weight plus Ribavirin (Rebetol, Schering Plough, Kenilworth, NJ, USA) that was administered orally at the starting daily dose of $400-800 \mathrm{mg} /$ day. Planned duration of treatment was 48 weeks. Patients who were HCV RNA-positive after 12 weeks of treatment were considered as nonresponders and treatment was stopped. All patients were monitored monthly during and after therapy. Complete blood count, AST, ALT, bilirubin, creatinine and prothrombin time were checked monthly or more frequently, if needed. Serum HCV RNA levels were checked by RT-PCR before therapy, at 12 and 24 weeks, at the end of therapy (Quantitative test: HCV Monitor; sensitivity $>600 \mathrm{UI} / \mathrm{mL}$ ).

\section{Statistical Analysis}

All data were tabulated and processed with SPSS software (Statistical Product and Service Solutions, version 21, SSPS Inc, Chicago, IL, USA) and Windows XP (Microsoft Corporation, Redmond, Washington, USA). Qualitative data were expressed in frequency and percentage and analyzed with the chi-square test. Quantitative data were expressed as the mean and standard deviation and were compared with the $t$ test. The previous (preoperative, intraoperative and postoperative) variables were descreptively studied. Univariate analysis and then multivariate analysis for significant predictors in univariate analysis were done to detect the relationship between the previous data and overall HCV recurrence and between recurrence variables (Occurrence of recurrence and its management) and overall survival of patients in the follow up period after LDLT. The Kaplan-Meier method was applied for survival analysis and time to event analysis and compared using log-rank tests. In all tests, a $P$ value of $<0.05$ was considered significant and a $P$ value of $<0.01$ was highly significant.

\section{Results}

\section{Characteristics of the fifty five HCV patients and their donors}

They were classified as $49(89.1 \%)$ males, and $6(19.9 \%)$ females. Their mean age was 46.3 years \pm 5.07 . Their donors were classified as $37(67.3 \%)$ males and 18 (32.7\%) females, their mean age was 26.8 years \pm 8.03 . They were classified according to Child-Pugh score into $1(1.8 \%)$ class A, $12(21.8 \%)$ class B, and $42(76.4 \%)$ class C, and their mean MELD score was $17.2 \pm 3.7 .(47.3 \%)$ of them had co morbidity, in the form of Hypertension and DM, while the incidence of CMV infection was $(23.6 \%)$ in them (N.B. CMVIgG was positive in all donors and recipients, 2 patients developed CMV viremia and invasive CMV. Both had elevation of the liver enzymes, bilirubin plus GIT symptoms e.g. nausea, vomiting, colics and diarrhea. One of them responded to 4 weeks ganciclovir IV therapy and the second unfortunately died 
Citation: Salem EH, Taha M, Aziz A, Alsebaey A, El-Ella KA, et al. (2014) Recurrent Hepatitis C Virus (Genotype 4) Infection after Living Donor Liver Transplantation: Risk Factors and Outcome. J Liver 3: 148. doi:10.4172/2167-0889.1000148

Page 3 of 6

with graft failure 6 months postoperatively). The regimen including FK, MMF and steroids was given to $89.1 \%$ of them (2 patients were not given FK and another 4 patients were not given MMF). While the regimen including Cyclosporine, MMF and steroids was given to $36.4 \%$ (18 patients were switched from FK to cyclosporine and 2 patients were given cyclosporine from the start) and the regimen including sirolomus, MMF and steroids was given to $10.9 \%$ (5 patients were shifted from FK to sirolomus and 1 patient was switched from cyclosporine to sirolomus). Acute rejection episodes occurred in 14 (25.5\%) of patients, and treated with steroid bolus Table 1 .

\section{HCV recurrence and its management}

In our series, the recurrence of hepatitis $C$ virus was universal in terms of viremia. The clinical recurrence of hepatitis $\mathrm{C}$ virus infection was found in $21(38.2 \%)$ of the 55 patients and diagnosed at a mean of $11.9 \pm 5.5$ months post transplantation. The mean fibrosis score of those 21 patients was $\mathrm{F} 2.24 \pm 1.09$ Ishak and the mean grade of inflammation was $6.86 \pm 2.220$. One of the recipients exhibited allograft cirrhosis. Sixteen $(76.1 \%)$ of the $21 \mathrm{HCV}$ patients was treated with PEG-IFN- $\alpha$ $2 \mathrm{~b}$ and Ribavirin, 13 (81.3\%) of the 16 patients completed the course of treatment with SVR (Table 2).

\section{Recipient and donor risk factors as predictors of $\mathrm{HCV}$ recurrence}

A- On univariate analysis, the following variable was found to be statistically highly significant predictors of recurrence: Occurrence of acute rejection episodes and administration of pulse steroid therapy

\begin{tabular}{|c|c|}
\hline $\begin{array}{l}\text { Donor age(years) }(\text { Mean } \pm \mathrm{SD}) \\
\text { Donor age(years) } \\
<31 \\
>31\end{array}$ & $\begin{array}{l}26.8 \pm 8.03 \\
38(69.1 \%) \\
17(30.9 \%)\end{array}$ \\
\hline Recipient age(years) (Mean \pm SD) & $46.3 \pm 7.9$ \\
\hline $\begin{array}{l}\text { Donor gender } \\
\text { males } \\
\text { females }\end{array}$ & $\begin{array}{l}37(67.3 \%) \\
18(32.7 \%)\end{array}$ \\
\hline $\begin{array}{l}\text { Recipient gender } \\
\text { males } \\
\text { females }\end{array}$ & $\begin{array}{c}49(89.1 \%) \\
6(19.9 \%)\end{array}$ \\
\hline $\begin{array}{l}\text { Child class } \\
\text { A } \\
\text { B } \\
\text { C }\end{array}$ & $\begin{array}{c}1(1.8 \%) \\
12(21.8 \%) \\
42(76.4 \%)\end{array}$ \\
\hline MELD score (Mean \pm SD) & $17.2 \pm 3.7$ \\
\hline Co morbidity & $26(47.3 \%)$ \\
\hline CMV infection & $13(23.6 \%)$ \\
\hline Calculated GRWR (Mean \pm SD) & $1.23 \pm 0.23$ \\
\hline Actual GRWR (Mean \pm SD) & $1.07 \pm 0.18$ \\
\hline Cold ischemia time $(\min )($ Mean $\pm S D)$ & $69.2 \pm 47.4$ \\
\hline Warm ischemia time $(\min )(($ Mean $\pm S D)$ & $47.7 \pm 15.3$ \\
\hline Plasma transfusion (units) (Mean \pm SD) & $5.2 \pm 6.4$ \\
\hline Duration of operation (hours) (Mean $\pm S D$ ) & $11.5 \pm 2.7$ \\
\hline \multirow{3}{*}{$\begin{array}{l}\text { Immunosuppression and steroid regimen } \\
\text { FK, MMF, steroids } \\
\text { Cyclosporine, MMF, steroids } \\
\text { sirolomus, MMF, steroids }\end{array}$} & \\
\hline & $\begin{array}{l}49(89.1 \%) \\
20(36.4 \%)\end{array}$ \\
\hline & $6(10.9 \%)$ \\
\hline Acute rejection episodes & $14(25.5 \%)$ \\
\hline Rejection activity index (RAI)/9 (Mean \pm SD) & $(5.5 \pm 1.1)$ \\
\hline
\end{tabular}

MELD: Model for end stage liver disease; CMV: Cytomegalovirus; GRWR:Graft recipient weight ratio; MMF: Mycophenolatemofetil

Table 1: Characteristics of the fifty five HCV patients and their donors. (acute rejection and HCV recurrence did not occur at the same time). However, infection with CMV and mean operative time of $12.490 \pm$ $1.8952 \mathrm{~h}$ were statistically significant predictors of recurrence, on the other hand there was no significant correlation between the following variables and $\mathrm{HCV}$ recurrence (donor and recipient age, donor and recipient gender, Child-Pugh class and MELD score, Co morbidity, immunosuppression and steroid regimen, Calculated and actual graft weight, calculated and actual GRWR, cold ischemia and warm ischemia times/minutes and amount of blood and plasma transfusion (Tables 3 and 4$)$.

B-On multivariate analysis by linear regression test, occurrence of acute rejection episodes and administration of pulse steroid therapy was found to be independent predictor of recurrence (Table 5).

\section{Outcome of patients}

The mortality of all, non-recurrent and recurrent patients were

\begin{tabular}{|l|c|}
\hline Cumulative recurrence rate & $21 / 55(38.2 \%)$ \\
\hline Recurrence onset (months) (Mean \pm SD) & $(11.9 \pm 5.5)$ \\
\hline Management of recurrence & $16 / 21(76.1 \%)$ \\
\hline Outcome of recurrence treatment & $13 / 16(81.3 \%)$ \\
SVR & $1 / 16(6.3 \%)$ \\
Non SVR & $2 / 16(12.4 \%)$ \\
Under treatment & $883,358.10 \pm 815,766.79$ \\
\hline Post transplantation PCR of recurrent cases & $6.86 \pm 2.220$ \\
(Mean \pm SD) & $2.24 \pm 1.09$ \\
\hline Post transplantation biopsy of recurrent cases & \\
(Mean \pm SD)Grading/18 & $6.86 \pm 2.220$ \\
\hline Staging/6 & \\
\hline Histological activity index(HAI)/18 (Mean \pm SD) & 6.020 \\
\hline
\end{tabular}

SVR:Sustained virological response; PCR:Polymerase chain reaction Table 2: HCV recurrence and its management

\begin{tabular}{|l|c|c|}
\hline Category & Recurrence No( \% ) & p-value \\
\hline Number of patients & $21 / 55(38.2 \%)$ & \\
\hline Donor age(years) & $16 / 38(42.1 \%)$ & \\
$<31$ & $5 / 17(29.4 \%)$ & $>0.05$ \\
$>31$ & & \\
\hline Recipient gender & $20 / 49(40.8 \%)$ & $>0.05$ \\
- Male & $1 / 6(16.7 \%)$ & \\
- Female & & \\
\hline Child class & $1 / 1(100.0 \%)$ & \\
A & $8 / 12(33.3 \%)$ & $>0.05$ \\
B & $16 / 42(38.1 \%)$ & \\
C & & $>0.05$ \\
\hline Co morbidity & $11 / 29(37.9 \%)$ & \\
- No & $10 / 26(38.4 \%)$ & \\
- Yes & & $>0.047$ \\
\hline CMV infection & $13 / 42(31 \%)$ & $>0.05$ \\
No & $8 / 13(61.5 \%)$ & \\
Yes & & \\
\hline Immunosuppression and steroid regimen & $17 / 49(34.7 \%)$ & $>0.05$ \\
FK, MMF, steroids & $8 / 20(40.0 \%)$ & $>05$ \\
Cyclosporine, MMF, steroids & $3 / 6(50 \%)$ & \\
Sirolomus, MMF, steroids & $9 / 41(22.0 \%)$ & \\
\hline Acute rejection episodes & $12 / 14(85.7 \%)$ & \\
No & & \\
Yes & & \\
\hline
\end{tabular}

CMV: Cytomegalovirus; MMF: Mycophenolatemofetil

Table 3: Recipient and donor risk factors as predictors of HCV recurrence. 


\begin{tabular}{|l|c|c|c|}
\hline Category & $\begin{array}{c}\text { Recurrence (Mean } \\
\text { Std. deviation) }\end{array}$ & $\begin{array}{c}\text { No recurrence (Mean } \\
\text { Std. deviation) }\end{array}$ & p-value \\
\hline Recipient age & $48.38 \pm 4.165$ & $45.15 \pm 9.410$ & $>0.05$ \\
\hline MELD & $17.10 \pm 3.520$ & $17.29 \pm 3.889$ & $>0.05$ \\
\hline Donor Age & $26.05 \pm 8.115$ & $27.38 \pm 8.068$ & $>0.05$ \\
\hline BMI of Donor & $25.66 \pm 3.824$ & $25.17 \pm 3.552$ & $>0.05$ \\
\hline Calculated graft weight & $920.10 \pm 148.509$ & $938.97 \pm 168.040$ & $>0.05$ \\
\hline Calculated GRWR & $1.1400 \pm .21984$ & $1.1871 \pm .24570$ & $>0.05$ \\
\hline Actual graft wt & $890.48 \pm 103.222$ & $844.12 \pm 152.139$ & $>0.05$ \\
\hline Actual GRWR & $1.0905 \pm .16770$ & $1.0721 \pm .19770$ & $>0.05$ \\
\hline $\begin{array}{l}\text { Cold ischemia time/ } \\
\text { minutes }\end{array}$ & $72.14 \pm 31.645$ & $67.42 \pm 55.637$ & $>0.05$ \\
\hline $\begin{array}{l}\text { Warm ischemia time/ } \\
\text { minutes }\end{array}$ & $50.48 \pm 15.484$ & $46.03 \pm 15.165$ & $>0.05$ \\
\hline Operative time/ $\mathrm{h}$ & $12.490 \pm 1.8952$ & $10.934 \pm 3.0282$ & .023 \\
\hline Blood transfusion/unit & $5.19 \pm 5.046$ & $4.18 \pm 5.072$ & $>0.05$ \\
\hline $\begin{array}{l}\text { Plasma transfusion/ } \\
\text { unit }\end{array}$ & $7.67 \pm 8.398$ & $3.71 \pm 4.373$ & .056 \\
\hline
\end{tabular}

BMI: Body mass index

Table 4: Recipient and donor risk factors as predictors of HCV recurrence.

\begin{tabular}{|c|c|c|c|}
\hline \multirow{2}{*}{ Model } & \multirow{2}{*}{$\mathrm{P}$ value } & \multicolumn{2}{|c|}{$95.0 \%$ Confidence Interval } \\
\cline { 3 - 4 } & & Lower bound & Upper bound \\
\hline CMV & 0.359 & 0.143 & 0.387 \\
\hline Operative time/ $\mathrm{h}$ & 0.101 & 0.074 & 0.007 \\
\hline Acute rejection & 0.000 & 0.316 & 0.834 \\
\hline
\end{tabular}

BMI: Body mass index

Table 5: Multivariate analysis by linear regression of predictors of $\mathrm{HCV}$ recurrence.

9.1\%, $8.8 \%$ and $9.5 \%$ respectively. While overall 1,3 and 5 year survival of all patients was $94.5 \%, 90.9 \%$ and $90.9 \%$ respectively. On the other hand the overall 1,3 and 5 year's survival of patients with and without recurrence was $95.2 \%, 90.5 \%$ and $90.5 \%$ and $94.1 \%, 91.2 \%$ and $91.2 \%$ respectively (Table 6 and Figure 1).

V- On univariate analysis, the following variables were found to be statistically non-significant predictors of survival despite a trend towards survival: Absence of recurrence of $\mathrm{HCV}(91.2 \%)$ and treatment of recurrence (93.8\%) (Table 7).

\section{Discussion}

The rates and severity of HCV recurrence are highly variable and are probably related to the complex interplay of host factors, iatrogenic influences (e.g., immunosuppressant, antiviral treatment), and possibly genetic variability of the allograft [9]. The incidence of recurrence in our study was $21 / 55$ of patients $(38.2 \%)$ during the follow up period (6 months to 60 months).while, 1,3 and 5 years HCV recurrence was (25.4\%, 36.3\% and $38.2 \%$ respectively). Similarly, in the studies by Yosry et al. in 2009 [2], and Raffaella et al. in 2010 [4], HCV recurrence was found in 23/74(31.1\%), and 25/45(46.2\%) respectively. In contrast, in a study by Francisco et al. in 2006 [10], serological recurrence of HCV in their study was $100 \%$, and histological recurrence was $92 \%$, they found that 1-,3- and 5- years HCV recurrence was $(51.5 \%, 83.5 \%$, and $92 \%$ respectively). This is due to recurrent $100 \%$ viraemia after graft reperfusion, and high reinfection due to immunosuppression.

While overall survival of all, non-recurrent, and recurrent HCV patients was $90.9 \%, 91.2 \%$ and $90.5 \%$ respectively. Similarly, Yosry et al. in 2009 [2], found (91.3\%) 3-y HCV survival rate in their recurrent patients. However, in a study by Doris et al. in 2010 [11], HCV survival was (95\%); he concluded that the majority of patients with recurrent HCV develop graft dysfunction affecting survival, and leading to

\begin{tabular}{|l|c|c|c|}
\hline Characteristic & $\begin{array}{c}\text { All HCV } \\
\text { recipients } \\
\text { No (\%) }\end{array}$ & $\begin{array}{c}\text { Non recurrent } \\
\text { recipients } \\
\text { No (\%) }\end{array}$ & $\begin{array}{c}\text { Recurrent } \\
\text { recipients } \\
\text { No (\%) }\end{array}$ \\
\hline Total number & $55(100 \%)$ & $34(100 \%)$ & $21(100 \%)$ \\
\hline Mortality & $5(9.1 \%)$ & $3(8.8 \%)$ & $2(9.5 \%)$ \\
\hline Over all & $52(94.5 \%)$ & $32(94.1 \%)$ & $20(95.2 \%)$ \\
1-year survival & $50(90.9 \%)$ & $31(91.2 \%)$ & $19(90.5 \%)$ \\
3-year survival & $50(90.9 \%)$ & $31(91.2 \%)$ & $19(90.5 \%)$ \\
\hline 5-year survival & & & \\
\hline
\end{tabular}

Table 6: Outcome of patients.

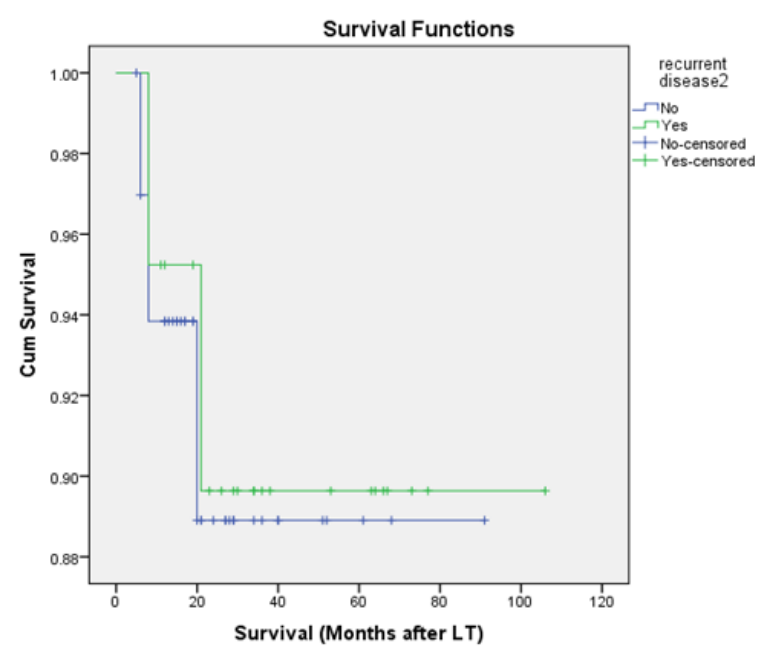

Figure 1: Kaplan-Meier survival curve of recurrent and non-recurrent patientsin the follow up period (6-60 months) Log Rank: 0.878 -value: $<0.05$.

\begin{tabular}{|l|c|c|}
\hline Characteristic & Survival No (\%) & p-value \\
\hline Number of patients & $50 / 55(90.9 \%)$ & \\
\hline Recurrence of 1ry disease & & \\
Yes & $19 / 21(90.5 \%)$ & $>0.05$ \\
No & $31 / 34(91.2 \%)$ & \\
\hline Recurrence onset (months) Mean \pm SD & $5.0720 \pm 8.46$ & $>0.05$ \\
\hline Treatment of recurrence & & \\
Yes & $15 / 16(93.8 \%)$ & $>0.05$ \\
\hline No & $4 / 5(80 \%)$ & \\
\hline
\end{tabular}

Table 7: Recurrence variables as predictors of survival.

cirrhosis. In contrast, in our study, $1(4.7 \%)$ of the recurrent 21 patients developed graft cirrhosis. Furthermore, antiviral treatment in transplant patients is feasible and does not induce severe immunological effects, so, it is recommended in recurrent HCV to use antiviral in the form of PEG plus Ribavirin, with good SVR and survival [6]. In the current study, we found that, survival was better(93.8\%) in patients who underwent management of their recurrent HCV than who did not undergo management (80\%), Also in a study by Raffaella et al. in 2010 [4], it was found that long term maintenance Ribavirin monotherapy was associated with reduced fibrosis progression in recurrent HCV patients and better survival.

In the recent study, recipient age wasn't a significant predictor of HCV recurrence. Similarly, in the study by Yosry et al. in 2009 [2], and Doris et al. [11], there was no correlation between recipient age and $\mathrm{HCV}$ recurrence. In contrast, in a study by Charlton and Menon 
[5], older recepients, were significantly correlated with more severe recurrence of $\mathrm{HCV}$, perhaps because older patients are less able to mount an effective immune response against viral recurrence [12].

There was a trend towards significant HCV recurrence in the current study regarding male recipients. In contrast, female gender has been associated with a severe course of recurrent hepatitis $C$, and male recipient was significant predictor of fibrosis progression in recurrent HCV in the studies by Forman et al. in 2002 [13], and Raffaella et al. in 2010 [4] respectively.

It was found that there was no significant correlation between donor age and recurrence in the present study, similarly, in the studies by Yosry et al. in 2009 [2] and Doris et al. in 2010 [11] there were no correlation between donor age and HCV recurrence, In contrast, in the studies by (Berenguer, 2003 [14], Charlton and Menon, 2005 [5], Cameron et al. [12], and Francisco et al. [10] donor age $<31$ years was significant predictor of HCV recurrence, perhaps because older grafts are less able to mount an effective immune response against viral recurrence [12].

We found no significant correlation between donor gender and HCV recurrence, also, in the study by Yosry et al. [2], there was no correlation between donor gender and HCV recurrence, on the other hand, Cameron et al. in 2006 [2], found that male donors were significant predictors of $\mathrm{HCV}$ recurrence.

We studied the correlation between the post-transplant HCV recurrence and both the pretransplant Child-Pugh classification and the Model for End-Stage Liver Disease(MELD) score and found no significant correlation, this result is in consistence with one important recent study in which no significant correlation was found between the pre transplantation severity of liver disease and recurrence of $\mathrm{HCV}$ after transplantation, it is the study by Yosry et al. [2], in which pretransplant Child-Pugh classification and the MELD score, were non-significant predictors of $\mathrm{HCV}$ recurrence. Co-morbidity is a host factor associated with HCV recurrence [15]. In contrast, it was not a significant predictor of recurrence in the current study despite the higher recurrence rate in patients with Co-morbidity.

Cytomegalovirus (CMV) infection has been strongly associated with increased severity of HCV recur $\neg$ rence [5]. Similarly, in the current study there was significant association between CMV infection, and recurrence, inversely, Doris and associates in 2010 [11], concluded that CMV had no impact on HCV recurrence.

The current study did not show any significant correlation between graft size, and GRWR and HCV recurrence, similarly Yosry et al. [2], did not find significant association between the graft volume or between GRWR of $<1 \%$, or $>1 \%$, and HCV recurrence, despite the larger graft volume $(836 \pm 142 \mathrm{~g})$ in non-recurrent group in their study.

Immunosuppression is considered a main factor in the severity of recurrent hepatitis $C$ virus infection [16], because of its effect on viral replication and its suppression of the systemic immune responses, both of which can lead to accelerated hepatocellular damage and fibrosis. So, modifying immunosuppression are the main means of preventing disease progression [2]. Doris et al. in 2010 [2], found that patients in the Calcineurin inhibitors group showed a significant trend towards HCV recurrence as compared to patients on SIR therapy during their follow up period. In contrast, in the current study, the regimen of immunosuppression (tacrolomus based, cyclosporine based or sirolomus based), was not significantly associated with disease recurrence. The possible explanation for that finding is that steroids were administered to the study subjects for only 3 months, and monotherapy was the standard immunosuppressive regimen in our center. While, Francisco et al. [10], and Yosry et al. [2], found no significant correlation between the regimen of immunosuppression, and hepatitis $\mathrm{C}$ virus recurrence. Also, in the study done by Balbi et al. in 2009 [6], and Jiménez-Pérez et al. in 2010 [17], there was no significant association between tacrolomus based or cyclosporine based immunosuppression and SVR, after treatment for recurrent hepatitis C virus infection after liver transplantation. Francisco and associates in 2006 [10], found significant correlation between MMF, and low HCV recurrence. On the other hand, several authors reported that MMF administration was not associated with low HCV recurrence [18]. Similarly, in the present study we did not show significant correlation between MMF administration, and disease recurrence.

Treatment with steroids for acute cellular rejection episodes has been reported to be a risk factor for the severity of HCV recurrence [19]. In the studies by Francisco et al. in 2006 [10] and Doris et al. in 2010 [11], there was significant correlation between pulse steroids andHCV recurrence. Similarly, we found a high significant association between acute rejection episodes and pulse steroids administration and HCV recurrence in the univariate analysis, this acute rejection and pulse steroids administration was independent predictor of recurrence in the multivariate analysis.

In conclusion, the occurrence of acute rejection was independent predictor of HCV recurrence post LDLT, so its prevention is required to decrease this recurrence. Similarly, prevention of CMV infection and decreasing operative time is important to decrease post-transplant HCV recurrence.

\section{Acknowledgement}

Forms of support received by each author for this study included good selection of cases, instructive supervision, continuous guidance, valuable suggestions and good instructions. No grant or other financial support was received for this study.

\section{References}

1. Muiesan $P$, Vergani $D$, Mieli-Vergani $G$ (2007) Liver transplantation in children J Hepatol 46: 340-348.

2. Yosry A, Abdel-Rahman M, Esmat G, El-Serafy M, Omar A, et al. (2009) Recurrence of hepatitis $C$ virus (genotype 4) infection after living-donor liver transplant in Egyptian patients. Exp Clin Transplant 7: 157-163.

3. Caremani M, Tacconi D, Giorni P, Lapini L, Corradini S, et al. (2007) Clinica management of patients with recurrent viral hepatitis after liver transplantation. J Ultrasound 10: 46-52.

4. Lionetti R, Tisone G, Palmieri G, Almerighi C, Anselmo A, et al. (2010) Maintenance ribavirin monotherapy delays fibrosis progression in liver transplant recipients with recurrent hepatitis $C$ at high risk of progression. Dig Liver Dis 42: 297-303.

5. Charlton MR, Menon KV (2005) Late complications of liver transplantation and recurrence of disease. In: Ronald WB, Goran KK (Eds.), Transplantation of the liver (2ndedn) 65: 995-1017.

6. Balbi E, Leal CR, Pacheco-Moreira LF, Pousa FS, Covelo MC, et al. (2009) Treatment for recurrent hepatitis $C$ virus infection after liver transplantation. Transplant Proc 41: 891-894.

7. (1994) Intraobserver and interobserver variations in liver biopsy interpretation in patients with chronic hepatitis C. The French METAVIR Cooperative Study Group. Hepatology 20: 15-20.

8. Ishak K, Baptista A, Bianchi L, Callea F, De Groote J, et al. (1995) Histological grading and staging of chronic hepatitis. J Hepatol 22: 696-699.

9. Rosen HR (2000) Disease recurrence following liver transplantation. Clin Liver Dis 4: 675-689.

10. Sánchez-Bueno F, Ortiz ML, Bermejo J, Miras M, Pons JA, et al. (2006) 
Citation: Salem EH, Taha M, Aziz A, Alsebaey A, El-Ella KA, et al. (2014) Recurrent Hepatitis C Virus (Genotype 4) Infection after Living Donor Liver Transplantation: Risk Factors and Outcome. J Liver 3: 148. doi:10.4172/2167-0889.1000148

Prognostic factors for $\mathrm{HCV}$ recurrence in patients undergoing liver transplantation. Transpllmmunol. 17: 47-50.

11. Doris W, Daniela K, Silvia S, Estrella J, Helmut M, et al. (2010) Sirolimus has a potential to influence viral recurrence in $\mathrm{HCV}$ positive liver transplant candidates. International Immunopharmacology 20: 200-207.

12. Cameron AM, Ghobrial RM, Hiatt JR, Carmody IC, Gordon SA, et al. (2006) Effect of nonviral factors on hepatitis $C$ recurrence after liver transplantation. Ann Surg 244: 563-571.

13. Forman LM, Lewis JD, Berlin JA, Feldman HI, Lucey MR (2002) The association between hepatitis $C$ infection and survival after orthotopic liver transplantation. Gastroenterology 122: 889-896

14. Berenguer M (2003) Host and donor risk factors before and after liver transplantation that impact HCV recurrence. Liver Transpl 9: S44-47.
15. Berenguer M, López-Labrador FX, Wright TL (2001) Hepatitis C and liver transplantation. J Hepatol 35: 666-678.

16. Charlton M (2003) Liver biopsy, viral kinetics, and the impact of viremia on severity of hepatitis $C$ virus recurrence. Liver Transpl 9: S58-62.

17. Jiménez-Pérez $M$, Sáez-Gómez AB, Pérez-Daga JA, Lozano-Rey JM, de la Cruz-Lombardo J, et al. (2010) Hepatitis C virus recurrence after liver transplantation: analysis of factors related to sustained viral response. Transplant Proc 42: 666-668.

18. Firpi RJ, Nelson DR, Davis GL (2003) Lack of antiviral effect of a short course of mycophenolatemofetil in patients with chronic hepatitis $C$ virus infection. Liver Transpl 9: 57-61.

19. Ciccorossi P, Maina AM, Oliveri F, Petruccelli S, Leandro G, et al. (2007) Vira load 1 week after liver transplantation, donor age and rejections correlate with the outcome of recurrent hepatitis C. Liver Int 27: 612-619. 